\title{
Balloon Kyphoplasty for the Treatment of Acute Vertebral Compression Fractures: 2-Year Results From a Randomized Trial
}

\author{
Steven Boonen, ${ }^{1}$ Jan Van Meirhaeghe, ${ }^{2}$ Leonard Bastian, ${ }^{3}$ Steven R Cummings, ${ }^{4}$ Jonas Ranstam, ${ }^{5}$ \\ John B Tillman, ${ }^{6}$ Richard Eastell, ${ }^{7}$ Karen Talmadge, ${ }^{6}$ and Douglas Wardlaw ${ }^{8}$ \\ ${ }^{1}$ Leuven University Division of Geriatric Medicine, Katholieke Universiteit Leuven, Leuven, Belgium \\ ${ }^{2}$ Dienst Orthopedie en Traumatologie, Algemeen Ziekenhuis Sint-Jan Brugge-Oostende AV, Brugge, Belgium \\ ${ }^{3}$ Klinikum Leverkusen, Leverkusen, Germany \\ ${ }^{4}$ San Francisco Coordinating Center, California Pacific Medical Center Research Institute, and Department of Epidemiology and \\ Biostatistics, University of California San Francisco, San Francisco, CA, USA \\ ${ }^{5}$ Swedish National Competence Centre for Musculoskeletal Disorders at Lund University Hospital, Lund, Sweden \\ ${ }^{6}$ Medtronic Spine LLC, Sunnyvale, CA, USA \\ ${ }^{7}$ Academic Unit of Bone Metabolism, University of Sheffield, Sheffield, United Kingdom \\ ${ }^{8}$ Orthopaedic Department, Woodend Hospital, NHS Grampian, Aberdeen, United Kingdom
}

\begin{abstract}
Vertebral fractures are often painful and lead to reduced quality of life and disability. We compared the efficacy and safety of balloon kyphoplasty to nonsurgical therapy over 24 months in patients with acute painful fractures. Adults with one to three vertebral fractures were randomized within 3 months from onset of pain to undergo kyphoplasty $(n=149)$ or nonsurgical therapy $(n=151)$. Quality of life, function, disability, and pain were assessed over 24 months. Kyphoplasty was associated with greater improvements in Short-Form 36 (SF-36) Physical Component Summary (PCS) scores when averaged across the 24-month follow-up period compared with nonsurgical therapy [overall treatment effect 3.24 points, 95\% confidence interval $(\mathrm{Cl})$ 1.47-5.01, $p=.0004$ ]; the treatment difference remained statistically significant at 6 months $(3.39$ points, $95 \% \mathrm{Cl} 1.13-5.64, p=.003)$ but not at 12 months (1.70 points, $95 \% \mathrm{Cl}-0.59$ to 3.98 , $p=.15$ ) or 24 months ( 1.68 points, $95 \% \mathrm{Cl}-0.63$ to $3.99, p=.15$ ). Greater improvement in back pain was observed over 24 months for kyphoplasty (overall treatment effect -1.49 points, $95 \% \mathrm{Cl}-1.88$ to $-1.10, p<.0001$ ); the difference between groups remained statistically significant at 24 months $(-0.80$ points, $95 \% \mathrm{Cl}-1.39$ to $-0.20, p=.009)$. There were two device-related serious adverse events in the second year that occurred at index vertebrae (a spondylitis and an anterior cement migration). There was no statistically significant difference between groups in the number of patients (47.5\% for kyphoplasty, $44.1 \%$ for control) with new radiographic vertebral fractures; fewer fractures occurred ( 18\%) within the second year. Compared with nonsurgical management, kyphoplasty rapidly reduces pain and improves function, disability, and quality of life without increasing the risk of additional vertebral fractures. The differences from nonsurgical management are statistically significant when averaged across 24 months. Most outcomes are not statistically different at 24 months, but the reduction in back pain remains statistically significant at all time points. (C) 2011 American Society for Bone and Mineral Research.
\end{abstract}

KEY WORDS: BALLOON KYPHOPLASTY; VERTEBRAL FRACTURE; OSTEOPOROSIS

\section{Introduction}

Cind nical vertebral fractures affect an estimated 1.4 million individuals worldwide every year. ${ }^{(1-4)}$ It has been estimated that medical costs owing to spine fracture in the United States exceeded $\$ 1$ billion in 2005, an amount predicted to surpass $\$ 1.6$ billion by $2025 .^{(4)}$
Current therapies for vertebral fractures include nonsurgical and surgical treatment. Despite nonsurgical management, including analgesia, bed rest, physiotherapy, and back bracing, pain sometimes resolves slowly and can persist. ${ }^{(5)}$ Patients with vertebral fractures have physical deformities that affect functional and mobility outcomes as well as psychosocial outcomes. ${ }^{(6,7)}$ Furthermore, vertebral fractures lead to a reduced

Received in original form October 2, 2010; revised form December 21, 2010; accepted February 3, 2011. Published online February 17, 2011 Address correspondence to: Douglas Wardlaw, MB, ChB, ChM, FRCSEd, Grampian Orthopaedic Department, Woodend Hospital, Aberdeen, United Kingdom. E-mail: d.wardlaw@nhs.net

Journal of Bone and Mineral Research, Vol. 26, No. 7, July 2011, pp 1627-1637

DOI: 10.1002/jbmr.364

(C) 2011 American Society for Bone and Mineral Research 
quality of life (QOL), as measured by physical, activities of daily living, emotional, and leisure parameters, ${ }^{(2,3,8)}$ as well as increased back pain, deterioration of physical function, and worse general health perception. ${ }^{(9)}$

Balloon kyphoplasty is a percutaneous procedure that aims to reduce pain and disability and correct vertebral body deformity. Catheters with inflatable bone tamps are placed into the affected vertebral body. Balloon inflation compacts the cancellous bone and pushes the endplates apart, which may at least in part restore vertebral body height and correct angular deformity. ${ }^{(10)}$ Once the balloon is removed, the resulting void is filled with viscous bone cement to stabilize the vertebral body. In contrast, vertebroplasty typically involves insertion of a catheter and injection of liquid cement into the body without creating a cavity for the cement; some vertebral deformity correction may be achieved but typically is not a goal. ${ }^{(11,12)}$

The objective of this study, the Fracture Reduction Evaluation (FREE), was to compare the effectiveness of kyphoplasty with that of standard nonsurgical management for the treatment of acute vertebral fractures owing to osteoporosis. Results for 12 months have been published, ${ }^{(13)}$ and we present the final 24month results here.

\section{Materials and Methods}

\section{Participants}

The FREE trial was a randomized, nonblinded trial comparing nonsurgical care alone with balloon kyphoplasty for the treatment of acute painful vertebral fractures. ${ }^{(13)}$ Patients were randomized from February 2003 through December 2005. All participants had at least one acute thoracic or lumbar $\left(T_{5}-L_{5}\right)$ vertebral fracture with bone marrow signal changes on magnetic resonance imaging (MRI) and at least one with 15\% decreased height compared with adjacent vertebrae. Painful vertebral fractures were diagnosed by the local investigator; up to three could be treated if they also had signal changes, rapidly progressive height loss, or pseudoarthrosis and were considered painful. Participants had self-assessed back pain of at least 4 on a scale from 0 (no pain) to 10 (worst pain imaginable) that started within the past 3 months and was not attributable to other causes. Vertebral fractures were included regardless of etiology; however, fractures owing to primary bone tumors, osteoblastic metastases, and high-energy trauma were excluded. Participants gave written informed consent before enrollment. The protocol and consent forms were approved by local ethics committees.

Sample size was based on the primary endpoint of change in the Short-Form 36 (SF-36) Physical Component Summary (PCS) score at 1 month. It was estimated that 75 patients per group provided $80 \%$ power with a two-sided $\alpha$ of $5 \%$ to detect a 0.5 standard deviation $(S D=10)$ for the 1-month difference in change in SF-36 PCS. To account for possible loss to long-term follow-up, 300 patients were enrolled. ${ }^{(13)}$

\section{Procedures}

Patients were randomly assigned in a 1:1 ratio to receive kyphoplasty or nonsurgical care using a computer-generated schedule. Study randomization was stratified for gender, fracture etiology, use of bisphosphonates at the time of enrollment, and use of systemic steroids at the time of enrollment but not for number of prevalent fractures per subject. A permuted block randomization (stratified as indicated) was generated using PROC PLAN (SAS version 8.0 was used for analyses; Cary, NC, USA) prior to study start and was concealed. The study was carried out at 21 investigational centers in 8 countries (Austria, Belgium, France, Germany, Italy, Sweden, the Netherlands, and the United Kingdom).

Balloon kyphoplasty was performed using introducer tools, inflatable bone tamps, and polymethyl methacrylate bone cement and delivery devices (manufactured by Medtronic Spine LLC, Sunnyvale, CA, USA) using a percutaneous, bilateral, transpedicular, or extrapedicular approach. ${ }^{(14)}$ Most procedures were performed under general anesthesia. A few patients had conscious or deep sedation with local anesthesia. Patients received analgesics, bed rest, bracing, physiotherapy, rehabilitation programs, and walking aids according to standard practices of participating physicians and hospitals, and all patients were referred for treatment with calcium and vitamin D supplements and antiresorptive or anabolic agents. Subsequent clinical fractures were to be treated according to original assignment.

The primary endpoint of the study was the change in quality of life (QOL) as measured by the PCS scale of the SF-36 at 1 month. ${ }^{(15)}$ Secondary endpoints included the EuroQOL 5-Dimension Questionnaire (EQ-5D) ${ }^{(16)}$ and SF-36 subscale scores, ${ }^{(15)}$ function as measured by the Roland Morris Disability Questionnaire (RMDQ), ${ }^{(17)}$ back pain using a visual-analogue scale (VAS; scale 0-10), ${ }^{(18)}$ limited days of activity and bed rest because of back pain during the previous 2 weeks, ${ }^{(19)}$ and patient satisfaction on a 20-point Likert scale (extremely dissatisfied to extremely satisfied). Outcomes were assessed at baseline/ screening and at 1, 3, 6, 12, and 24 months; back pain also was assessed at 7 days.

Adverse events (AEs) were coded according to the Medical Dictionary for Regulatory Activities (MedDRA). All serious AEs were reported if they were related to a procedure or device. All other serious AEs were reported if they occurred in at least $2 \%$ of patients or the $p$ value for the difference between groups was less than .2. All fracture AEs coded to system organ class (SOC) musculoskeletal disorders were reported.

Study case report forms (CRFs) were completed by a research study nurse for most study centers. Questionnaires were completed by patients; occasionally, a patient may have required a study nurse for assistance. Site investigators reviewed and signed all CRFs, and all CRFs were source verified for $100 \%$ of the patients.

Lateral spine radiographs were taken at baseline and at 3, 12, and 24 months and were assessed centrally (Bio-lmaging Technologies, Inc., Newtown, PA, USA); two radiologists independently used semiquantitative grading ${ }^{(20)}$ and quantitative morphometry ${ }^{(21)}$ to assess deformities. A new or worsening fracture was defined by consensus that deformity increased by one or more grades. If semiquantitative readings differed, a fracture was diagnosed if there was a $20 \%$ or greater decrease in vertebral body height compared with an adjacent normal vertebra or a third radiologist made a qualitative diagnosis. ${ }^{(22)}$ Patients were included in the analysis of fractures if at least seven vertebrae could be evaluated at baseline and follow-up. 


\section{Statistical analysis}

Results were analyzed by intent to treat, including all data available at baseline and follow-up from all (300) randomized patients (the full analysis set); we used repeated-measures analysis of variance using mixed models that assumed a compound symmetry covariance structure to perform an analysis using unbalanced data of the primary and secondary endpoints. ${ }^{(23)}$ To determine whether the effects changed over time, treatment, visit, and treatment-by-visit interaction were included in the model. Analyses of change scores included baseline as a covariate. The $t$ test was used to compare the calculated means at each time point. Patient proportions (AEs, medications, baseline fractures) for each group were compared using the stratified Cochran-Mantel-Haenszel chi-square test. All analyses included randomization stratification factors and baseline as covariates; no adjustments were made for multiple tests.

The proportion of patients with one or more new or worsening subsequent fractures was tested using Fisher's exact test. To derive total EQ-5D scores, Dolan utilities were applied. ${ }^{(24)}$ For quality-adjusted life-year (QALY) estimation, the area under the curve (AUC) was calculated using the trapezoidal rule. AUC was calculated for patients who had complete data at baseline and either 12 or 24 months. If a patient was missing intermediate visits, the available data were used to calculate AUC.

\section{Role of the funding source}

Medtronic Spine, LLC, contributed to the study design, data monitoring, and reporting of results and paid for statistical analysis (Advanced Research Associates, Mountain View, CA, USA), core laboratory services (BioClinica, Inc., Newtown, PA, USA), and editorial writing assistance (ApotheCom, San Francisco, CA, USA). All authors had complete access to summarized data and provided all analyses requested. An independent statistician (JR) received the entire data set and verified all statistical analyses and the primary endpoint data by comparing a $10 \%$ random sample with the CRFs. The publication committee (DW, JVM, LB, JR, and SB) and the consultants to the publication committee (SRC and RE), which did not include the sponsor, wrote the first draft of the article and had final responsibility for data analysis and interpretation, content approval, and the decision to submit for publication and were not compensated for writing the manuscript. SRC also contributed to study design. Authors from Medtronic Spine, LLC, contributed to study design (KT), data analysis and interpretation, and manuscript development and content (JBT and KT).

\section{Results}

Between February 2003 and December 2005, 1279 patients were screened and 300 were randomized to either the balloon kyphoplasty ( $n=149$ ) or nonsurgical $(n=151)$ groups (Fig. 1). Table 1 shows the baseline characteristics of the enrolled patients. Most patients $(n=215)$ had a single fracture identified and treated. The two groups were comparable at baseline, except for more patients with multiple fractures in the kyphoplasty group. Patient disposition is presented in Fig. 1. Ten patients assigned to kyphoplasty did not have the procedure within the study. One withdrew and underwent vertebroplasty instead; another assigned to kyphoplasty withdrew, received kyphoplasty outside the study, and returned for the 24-month visit. Fourteen patients assigned to the control group withdrew prior to 3 months and indicated that they intended to undergo surgery; 5 had 1-month assessments prior to any surgery. Of the 14, 5 returned and had 24-month assessments. Three additional control patients who terminated early also returned for 24month assessments and remained nonsurgically treated.

At 24 months, data were available for a total of 232 patients (120 kyphoplasty and 112 nonsurgical patients); 68 patients were no longer participating in the study. There were no statistically significant differences in baseline SF-36 PCS, EQ-5D, RMDQ, back pain scores, or number of baseline fractures between patients who completed 24 months of follow-up and patients who discontinued (data not shown).

Fewer patients assigned to kyphoplasty than to nonsurgical management received physical therapy or walking aids, back braces, wheelchairs, miscellaneous aids, or other therapy. At 12 months, 32 of 121 kyphoplasty patients (26.4\%) versus 45 of 107 nonsurgical management patients $(42.1 \%)$ used nonpharmacologic therapy ( $p=.016)$; the gap narrowed at 24 months, with 33 of 119 patients (27.7\%) versus 42 of 108 patients $(38.9 \%$, $p=.090)$.

Fewer kyphoplasty patients used pain medications through 12 months: 61 of 118 kyphoplasty patients (51.7\%) versus 69 of 101 control patients $(68.3 \%, p=.013)$. Pain medication use was similar between treatment groups at 24 months: 28 of 114 patients (24.6\%) versus 23 of 105 patients (21.9\%), respectively $(p=.74)$. Fewer kyphoplasty patients used opioid medications through 6 months: 37 of 124 kyphoplasty patients (29.8\%) versus 48 of 112 nonsurgical management patients $(42.9 \%, p=.042)$. Differences between kyphoplasty and control groups were similar in opioid usage at 12 months [33 of 118 (28.0\%) versus 34 of 101 (33.7\%) patients, respectively, $p=.38$ ] and 24 months [10 of $114(8.8 \%)$ versus 10 of 105 (9.5\%) patients, respectively, $p=1.0]$.

A similar proportion of patients were taking osteoporosis therapies (eg, bisphosphonates, vitamin D, and calcium) throughout the study. The proportions of patients taking bisphosphonates for at least 1 year in the kyphoplasty and nonsurgical groups were 87 of $121(71.9 \%)$ versus 75 of 113 (66.4\%), respectively, at 24 months ( $p=.39$ ). Numbers of patients taking vitamin $D$ in the kyphoplasty and nonsurgical groups were 103 of $121(85.1 \%)$ versus 90 of 113 (79.6\%), respectively, at 24 months $(p=.30)$. Numbers of patients taking calcium were 105 of $121(86.8 \%)$ versus 98 of $113(86.7 \%)$, respectively, at 24 months $(p=1.0)$.

\section{Efficacy}

The kyphoplasty group had significantly greater improvement (difference in change from baseline) in physical symptoms, as assessed by the 100-point PCS component of the SF-36 averaged across the 24 months ( 3.24 points, $95 \% \mathrm{Cl} 1.47-5.01, p=.0004$; 


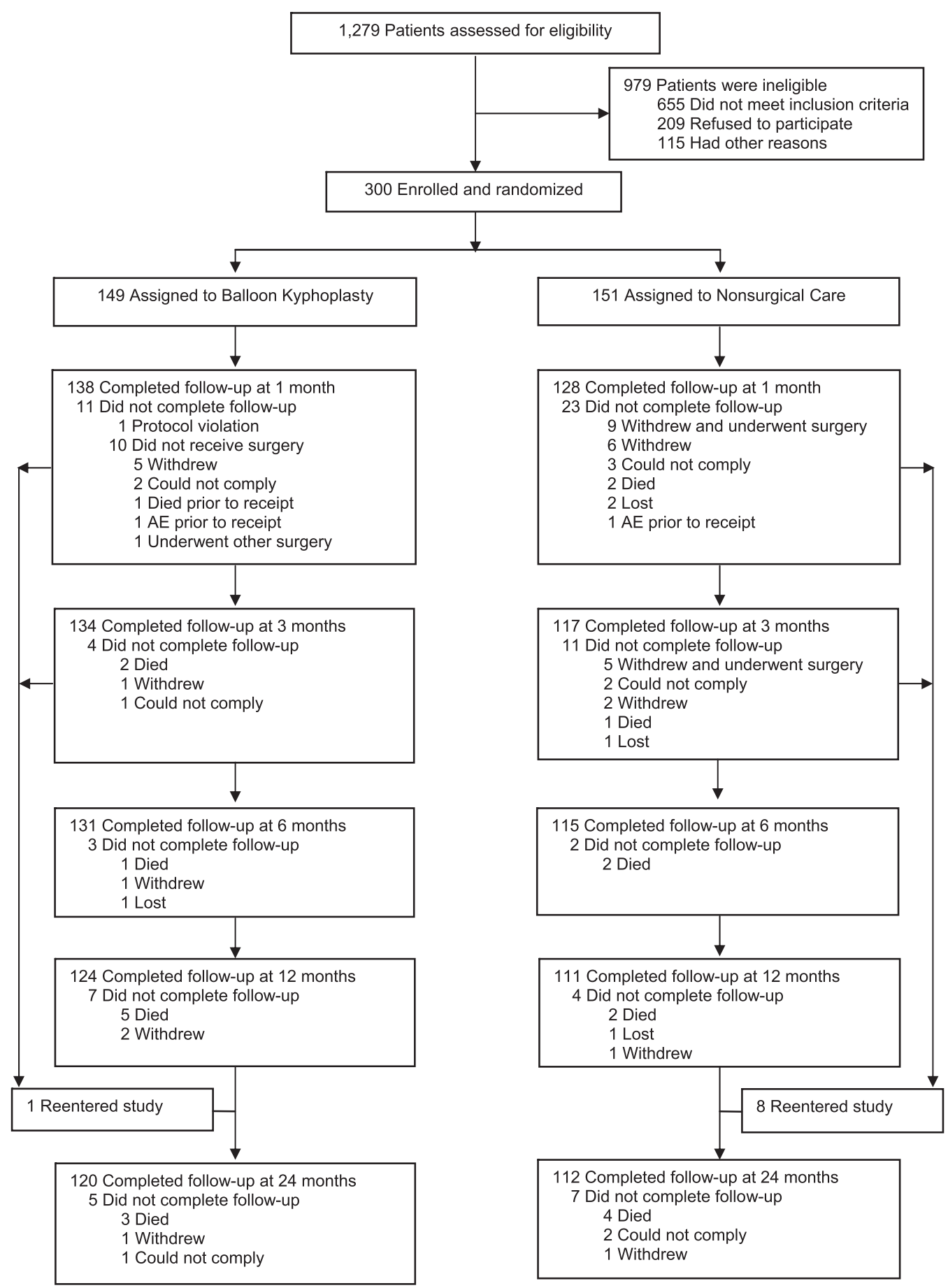

Fig. 1. Disposition of patients.

Fig. 2A). There was a significant treatment-by-visit interaction ( $p=.004)$, indicating that the treatment effect is not uniform across follow-up, a result from earlier improvement in the kyphoplasty group. The treatment difference remained statistically significant $(3.39$ points, $95 \% \mathrm{Cl} 1.13-5.64, p=.003)$ at 6 months but not at 12 months ( 1.70 points, $95 \% \mathrm{Cl}-0.59$ to $3.98, p=.15$ ) or 24 months ( 1.68 points, $95 \% \mathrm{Cl}-0.63$ to 3.99 , $p=.15)$.

The kyphoplasty group also had a significantly greater improvement in QOL, as assessed by the 1.0-point EQ-5D scale when averaged over 24 months of follow-up (treatment effect 0.12 points, $95 \% \mathrm{Cl}, 0.06-0.18, p=.0002 ;$ Fig. $2 B)$. The treatmentby-visit interaction was not significant $(p=.16)$. The area between the two EQ-5D curves, representing the difference in QALY, was $25.9 \%(p=.0007)$ in the first year and $15.4 \%$ in the second year $(p=.029)$.

The kyphoplasty group had a greater reduction in the 10-point back pain score averaged across the 24-month period $(-1.49$ points, $95 \% \mathrm{Cl}-1.88$ to $-1.10, p<.0001)$ with a significant treatment-by-visit interaction $(p<.0001$; Fig. $2 E)$; however, the 
Table 1. Baseline Patient Demographics and Disease Characteristics (Intent-to-Treat Population)

\begin{tabular}{|c|c|c|}
\hline Characteristics & Kyphoplasty $(n=149)$ & Control $(n=151)$ \\
\hline Patient age, mean (range), years & $72.2(44.5-95.2)$ & $74.1(52.8-89.1)$ \\
\hline Female, $n(\%)$ & $115(77.2)$ & $117(77.5)$ \\
\hline \multicolumn{3}{|l|}{ Underlying etiology, $n$ (\%) } \\
\hline Primary osteoporosis & $145(97.3)$ & $143(94.7)$ \\
\hline Secondary osteoporosis & $2(1.3)$ & $6(4.0)$ \\
\hline Multiple myeloma/metastatic & $2(1.3)$ & $2(1.3)$ \\
\hline Bisphosphonate use (effective at baseline), $n(\%)$ & $13(8.7)$ & $16(10.6)$ \\
\hline Glucocorticoid use, $n$ (\%) & $26(17.4)$ & $26(17.2)$ \\
\hline \multicolumn{3}{|l|}{ Baseline fractures, $n(\%)$} \\
\hline 1 & $100(67.1)$ & $115(76.2)$ \\
\hline 2 & $34(22.8)$ & $28(18.5)$ \\
\hline 3 & $15^{\mathrm{a}}(10.1)$ & $8(5.3)$ \\
\hline Baseline fracture location, $n(\%)$ & $n=214$ & $n=195$ \\
\hline Thoracic $\left(\mathrm{T}_{5}-\mathrm{T}_{9}\right)$ & $49(22.9)$ & $41(21.0)$ \\
\hline Thoracolumbar junction $\left(\mathrm{T}_{10}-\mathrm{L}_{2}\right)$ & $127(59.3)$ & $130(66.7)$ \\
\hline Lumbar $\left(\mathrm{L}_{3}-\mathrm{L}_{5}\right)$ & $38(17.8)$ & $24(12.3)$ \\
\hline \multicolumn{3}{|l|}{ Treated fractures per patient, $n(\%)$} \\
\hline $0^{\mathrm{b}}$ & $10(6.7)$ & $\mathrm{N} / \mathrm{A}$ \\
\hline 1 & $100(67.1)$ & \\
\hline 2 & $29(19.5)$ & \\
\hline 3 & $10(6.7)$ & \\
\hline Hip $T$-score (within $-6 /+3$ months of baseline) & $n=122$ & $n=121$ \\
\hline Normal $(\geq-1)$ & $30(24.6)$ & $18(14.9)$ \\
\hline Osteopenic $(<-1$ to $\geq-2.5)$ & $58(47.5)$ & $61(50.4)$ \\
\hline Osteoporosis $(<-2.5)$ & $34(27.9)$ & $42(34.7)$ \\
\hline Spine $T$-score (within $-6 /+3$ months of baseline) & $n=135$ & $n=128$ \\
\hline Normal $(\geq-1)$ & $28(20.7)$ & $20(15.6)$ \\
\hline Osteopenic $(<-1$ to $\geq-2.5)$ & $54(40.0)$ & $57(44.5)$ \\
\hline Osteoporosis $(<-2.5)$ & $53(39.3)$ & $51(39.8)$ \\
\hline
\end{tabular}

${ }^{a}$ One patient had a fourth index fracture identified between screening and planned surgery.

${ }^{\mathrm{b}}$ Ten balloon kyphoplasty patients did not receive surgery.

difference remained statistically significant at all follow-up visits and was -0.80 points at 24 months $(95 \% \mathrm{Cl}-1.39$ to -0.20 , $p=.009)$. Similar to back pain, the kyphoplasty group had a greater improvement in bodily pain, as assessed by the SF-36 subscale, during the 24 months of follow-up (average treatment effect 9.75 points, $95 \% \mathrm{Cl} 5.18-14.3, p<.0001$; Fig. 2F). The treatment-by-visit interaction was not statistically significant $(p=.52)$ for bodily pain change scores.

The reduction in disability as assessed by the 24-point RolandMorris scale also decreased with time (interaction $p=.0008$ ), with a -3.01 point difference averaged across 24 months $(95 \% \mathrm{Cl}$ -4.14 to $-1.89, p<.0001$; Fig. $2 C$ ). A treatment difference of -2.81 points was observed at 12 months $(95 \% \mathrm{Cl}-4.23$ to -1.40 , $p=.0001)$, but the difference at 24 months, -1.43 points, was not statistically significant $(p=.051)$. Similarly, the difference in number of days of limited activity (within a 2-week period) decreased over time (interaction $p=.017$ ) with an average -2.62-day difference over 24 months $(95 \% \mathrm{Cl}-3.68$ to -1.57 , $p<.0001)$; the -2.04 -day difference was statistically significant $(95 \% \mathrm{Cl}-3.57$ to $-0.51, p=.009)$ at 12 months. The -1.24 -day difference at 24 months was not statistically significant (Fig. 2D).
On a 20-point Likert scale, patients were more satisfied with the kyphoplasty procedure when averaged over 2 years (treatment effect 3.09 points, 95\% Cl 2.26-3.92, $p<.0001$ ); the difference was statistically significant at all time points including 24 months (2.31 points, $95 \% \mathrm{Cl} 1.19-3.43, p<.0001$ ).

\section{Safety}

There was no statistically significant difference in the number of patients with new radiographic fractures between the groups at 24 months. For kyphoplasty, 56 of 118 (47.5\%) patients had new fractures compared with 45 of 102 (44.1\%) in the nonsurgical group (3.4\% difference, $95 \% \mathrm{Cl}-16.5$ to $9.9, p=.68$ ); $53 \%$ of fractures occurred within 3 months, and $82 \%$ occurred within the first year (Table 2). Similarly, no statistically significant difference was found in the number of patients with adjacent radiographic fractures (Table 3); at 24 months, 28 of 118 patients (23.7\%) in the kyphoplasty group and 17 of 102 (16.7\%) in the nonsurgical group had fractures adjacent to the index fracture $(7 \%$ difference, $95 \% \mathrm{Cl}-17.6$ to $3.5, p=.24)$. There was no statistically significant difference in the number of subsequent painful 

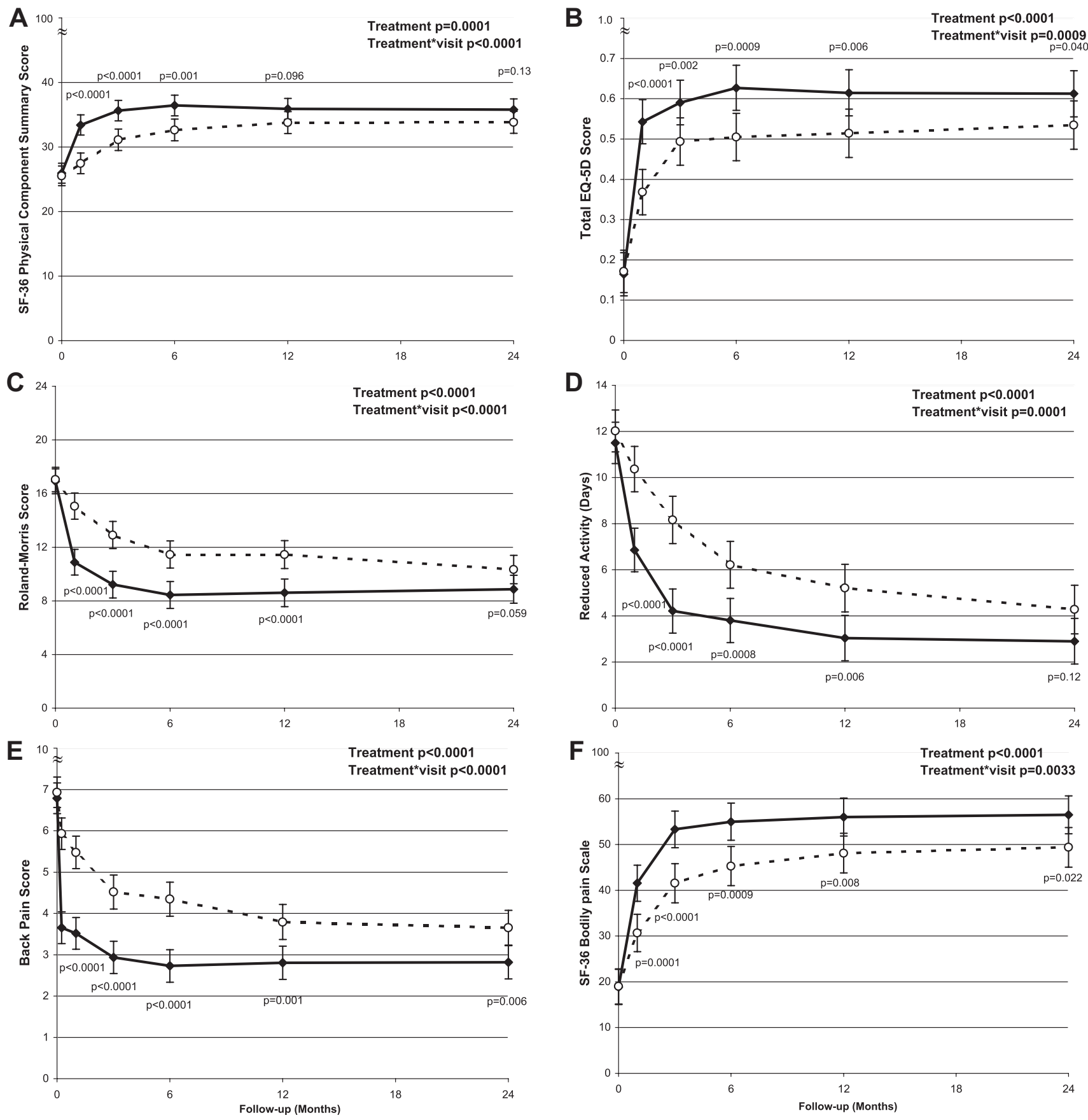

Fig. 2. Quality-of-life, disability, and pain assessments at baseline and after balloon kyphoplasty or nonsurgical management therapy. Group calculated means and 95\% confidence intervals are shown for balloon kyphoplasty (solid lines) and nonsurgical management (dotted lines) for ( $A$ ) SF-36 PCS (scale 0-100); (B) total EQ-5D scores (scale 0-1.0); (C) RMDQ (scale 0-24); (D) number of days within past 2 weeks that patients reported spending greater than half the day in bed because of back pain; ( $E$ ) back pain (scale $0-10,0$ ); ( $F$ ) SF-36 bodily pain (scale $0-100$ ). In panels $A$ through $F$, the treatment $p$ value refers to the average treatment effect difference during follow-up. The treatment-by-visit $p$ value relates to a time-related change of this difference. A significant treatment-by-visit interaction indicates that the treatment-effect difference is not constant throughout the 2-year study period. Individual time point comparison $p$ values are also shown.

vertebral fractures clinically recognized (26 in the kyphoplasty and 17 in the nonsurgical group, $6.2 \%$ difference, $95 \% \mathrm{Cl}-1.7$ to $14.1, p=.125)$. Although vertebral fractures that came to clinical attention were to be treated according to original randomization, only 12 of 26 kyphoplasty patients (46\%) were treated with new kyphoplasty. In the nonsurgical management group, 14 patients withdrew and intended to undergo surgery; 3 patients
(2\%) received kyphoplasty and 3 patients (2\%) received vertebroplasty for fractures that came to clinical attention and had 24-month assessments.

The overall frequency of patients with AEs and serious AEs (SAEs) was similar between treatment groups during the 2-year study (Table 4). Eleven patients (7.4\%) in the kyphoplasty group had new clinical fractures that the investigator considered 
Table 2. Patients With New Radiographic or Clinical Fractures in the Kyphoplasty and Nonsurgical Treatment Groups

\begin{tabular}{|c|c|c|c|}
\hline & Kyphoplasty & Control & $p$ Value \\
\hline \multicolumn{4}{|c|}{ Patients with new radiographic vertebral fractures, $n(\%)^{a}$} \\
\hline \multicolumn{4}{|l|}{$0-3$ months } \\
\hline None & $96(78.0 \%)$ & $73(73.0 \%)$ & 0.43 \\
\hline All subsequent & $27(22.0 \%)$ & $27(27.0 \%)$ & \\
\hline \multicolumn{4}{|l|}{$0-12$ months } \\
\hline None & $73(61.9 \%)$ & $61(61.6 \%)$ & 1.00 \\
\hline All subsequent & $45(38.1 \%)$ & $38(38.4 \%)$ & \\
\hline \multicolumn{4}{|l|}{$0-24$ months } \\
\hline None & $62(52.5 \%)$ & $57(55.9 \%)$ & 0.68 \\
\hline All subsequent & $56(47.5 \%)$ & $45(44.1 \%)$ & \\
\hline \multicolumn{4}{|l|}{ Patients with new clinical fractures, $n(\%)^{b}$} \\
\hline $0-24$ months & $n=149$ & $n=151$ & \\
\hline Vertebral fractures & $31(20.8 \%)$ & 27 (17.9\%) & 0.52 \\
\hline Considered painful vertebral fractures & $26(17.4 \%)$ & $17(11.3 \%)$ & 0.12 \\
\hline Considered "possibly or probably related"c & $11(7.4 \%)$ & $\mathrm{N} / \mathrm{A}$ & \\
\hline Nonvertebral fractures ${ }^{d}$ & $20(13.4 \%)$ & $15(9.9 \%)$ & 0.35 \\
\hline
\end{tabular}

possibly or probably related to the cement (Table 2); 10 of these patients had fractures that occurred during the first 12 months, and 2 patients had fractures during the second year of the study. One had a recurrent compression fracture SAE of the originally treated vertebral body 372 days after the original treatment. The cement had migrated anteriorly, and the anterior margin of the vertebral body was moved, possibly by the cement, in contact with the aorta, but no additional surgery was performed.

As reported previously, one hematoma at the surgical site and one exacerbation of a recurrent urinary tract infection (owing to catheterization) occurred within 2 days of surgery (Table 4). ${ }^{(13)}$ The patient who had the urinary tract infection also developed spondylitis near the cement in the treated vertebral body 376 days after surgery; the patient was treated with antibiotics, but inflammation had not resolved by 24 months. Biopsy indicated that the bacterium causing the urinary infection was the same as that causing the spondylitis. One patient from each treatment group terminated the study early owing to an $\mathrm{AE}$ during the 24-month follow-up period. There were 23 deaths, 12 in the kyphoplasty group and 11 in the nonsurgical group. All deaths were considered unrelated to treatment.

Table 3. Patients With New Radiographic Adjacent or Index Fractures Within 2 Years

\begin{tabular}{lccc}
\hline & Kyphoplasty & Control & $p$ Value \\
\hline Nonadjacent & $90(76.3 \%)$ & $85(83.3 \%)$ & 0.24 \\
Adjacent & $28(23.7 \%)$ & $17(16.7 \%)$ & \\
Nonindex & $113(95.8 \%)$ & $91(89.2 \%)$ & 0.072 \\
Index & $5(4.2 \%)$ & $11(10.8 \%)$ & \\
\hline
\end{tabular}

\section{Discussion}

We have shown previously that compared with nonsurgical management, kyphoplasty decreased disability and pain for 12 months. This extension to 24 months indicates that for most criteria, maximal benefit and stabilization for each group occur between 6 and 12 months. The improvements in physical function and disability observed during the first months after treatment remained, on the whole, but were no longer statistically significant at 2 years because the control group improved gradually. Ratings of pain and QOL remained significantly improved through 2 years (see Table 5 for summary).

Two randomized, controlled trials of vertebroplasty reported no beneficial effect of vertebroplasty on back pain compared with a sham procedure even within the first months after treatment, ${ }^{(11,12)}$ suggesting that the reductions in pain following vertebroplasty may be a nonspecific effect of the procedure and the natural history of vertebral fractures. However, neither of those studies had a control group with standard care (common practice) to assess the placebo effect of the sham intervention, and fractures were older $(<1$ year) than in our study ( $<3$ months), where patients had bone marrow signal changes on MRI. The sham-controlled studies used local anesthetic; we did not compare kyphoplasty with a sham procedure owing to the ethical consideration that many physicians prefer general anesthesia for kyphoplasty. The endpoints therefore were not blinded to the original treatment. It may be expected that the analgesic effects of a sham procedure occur soon after the intervention, as suggested by the sham-controlled trials, and would not be expected to last more than 3 months. The differences in back pain, SF-36 bodily pain, and ratings of QOL over 24 months in this trial suggest that kyphoplasty provides 
Table 4. Serious Adverse Events

\begin{tabular}{|c|c|c|}
\hline Number of patients & Kyphoplasty $(n=149)$ & Control $(n=151)$ \\
\hline With adverse events within 24 months & 134 & 134 \\
\hline Withdrew owing to adverse event & 1 & 1 \\
\hline With serious adverse events within 24 months & $74^{\mathrm{a}}$ & $73^{a}$ \\
\hline \multicolumn{3}{|l|}{ Blood and lymphatic systems disorders } \\
\hline Anemia & 3 & 2 \\
\hline \multicolumn{3}{|l|}{ Cardiovascular disorders } \\
\hline Angina pectoris & 2 & 5 \\
\hline Arrhythmia & 2 & 3 \\
\hline Myocardial infarction & $5^{\mathrm{b}}$ & 3 \\
\hline \multicolumn{3}{|l|}{ Gastrointestinal disorders } \\
\hline Rectal hemorrhage & 0 & 3 \\
\hline \multicolumn{3}{|l|}{ Hepatobiliary disorders } \\
\hline Cholelithiasis & 0 & 3 \\
\hline \multicolumn{3}{|l|}{ Infections } \\
\hline Sepsis/septic shock & 1 & 3 \\
\hline Urinary tract infection & $2^{c}$ & 3 \\
\hline \multicolumn{3}{|l|}{ Injury, poisoning, procedural complications } \\
\hline Hematoma & $1^{d}$ & 1 \\
\hline \multicolumn{3}{|l|}{ Musculoskeletal disorders (nonfracture) } \\
\hline Pain, back & 5 & 12 \\
\hline Spondylitis & $1^{\mathrm{c}}$ & 0 \\
\hline Neoplasms and cancer & 7 & 9 \\
\hline \multicolumn{3}{|l|}{ Psychiatric disorders } \\
\hline Depression & 3 & 1 \\
\hline \multicolumn{3}{|l|}{ Respiratory disorders } \\
\hline Dyspnea & 1 & 4 \\
\hline Pneumonia & 8 & 6 \\
\hline Pulmonary embolism & 4 & 1 \\
\hline \multicolumn{3}{|l|}{ Resulting in death ${ }^{\mathrm{e}}$} \\
\hline Cardiovascular & 5 & 5 \\
\hline Respiratory & 1 & 2 \\
\hline Cancer & 3 & 2 \\
\hline Other & 3 & 2 \\
\hline
\end{tabular}

${ }^{a}$ Patients may have had multiple serious adverse events; MedDRA categories and lower-level terms are listed where there was a procedure- or devicerelated SAE, any SAE occurring in $2 \%$ or more patients treated, or any SAE in which there was a difference between groups with a $p$ value of less than .2; MedDRA categories not listed include ear and labyrinth disorders, endocrine disorders, eye disorders, general disorders, immune system disorders, medical procedures, metabolic/nutritional disorders, nervous system disorders, renal and urinary disorders, reproductive disorders, and skin disorders.

${ }^{\mathrm{b}}$ One event occurred prior to planned surgery and resulted in death.

'One urinary tract infection SAE was considered procedure-related; the same patient had subsequent spondylitis at the treated level that was considered possibly cement-related.

${ }^{\mathrm{d} A}$ postoperative hematoma SAE was device-related.

'eserious adverse events in which the event resulted in death; none were device- or procedure-related.

benefits that are not attributable to the short-term effects of a nonspecific intervention. Nevertheless, the effects of kyphoplasty beyond that of a sham procedure can be assessed only in a sham-controlled trial. However, together the effects of kyphoplasty on pain, function, QOL, and disability were significantly greater than those obtained with nonsurgical management.

From reports of limited-activity days, we estimate that kyphoplasty patients had about 136 fewer days of limited activity during the 2-year trial than controls. Compared with nonsurgical management, there was a persistent average difference of 0.12 point as assessed by the EQ-5D rating of $\mathrm{QOL}$, which is greater than the minimum clinically important difference for that instrument (0.08). ${ }^{(25)}$ This difference is similar to that observed in randomized clinical trials for laminectomy for lumbar spinal stenosis treatment compared with nonsurgical management. ${ }^{(26)} \mathrm{A}$ recent cost-effectiveness analysis based on 12-month results of the FREE trial and modeled for a total of 3 years of posttreatment follow-up found that kyphoplasty incurs an incremental cost of $£ 1490$ (estimated \$2336) and incremental QALY gain of $16.9 \%$, yielding a cost/QALY of $£ 8800$ (\$13824) compared with nonsurgical care in the United Kingdom. ${ }^{(27)}$ This is below the $£ 20,000$ to $£ 30,000$ ( $\$ 31275$ to $\$ 46912$ ) per QALY threshold for the National Institute for Health and Clinical Excellence. ${ }^{(28)}$ The results from this trial will allow these analyses to be conducted with 24 months of follow-up data. 
Table 5. Summary Table of Statistically Significant Efficacy Results of Kyphoplasty Compared With Control

\begin{tabular}{|c|c|c|c|c|c|c|}
\hline & Treatment effect over 2 years & 1 Month & 3 Months & 6 Months & 12 Months & 24 Months \\
\hline EQ-5D & SS & SS & SS & SS & SS & SS \\
\hline Back pain & SS & SS & SS & SS & SS & SS \\
\hline SF-36 bodily pain & SS & SS & SS & SS & SS & SS \\
\hline Patient satisfaction & SS & SS & SS & SS & SS & SS \\
\hline RMDQ & SS & SS & SS & SS & SS & NS \\
\hline Activity days & SS & SS & SS & SS & SS & NS \\
\hline SF-36 PCS & SS & SS & SS & SS & NS & NS \\
\hline Opioids for pain & NA & SS & SS & SS & NS & NS \\
\hline Pain medications & NA & SS & SS & SS & SS & NS \\
\hline Nonpharmacologic therapy & NA & SS & SS & SS & SS & NS \\
\hline
\end{tabular}

SS = statistically significant; NS = not significant; NA = not applicable.

Patients who underwent kyphoplasty reported greater satisfaction with treatment than those who were assigned to nonsurgical care. However, patients were aware of their assignment, and their responses might have been affected by this.

Our randomized data are consistent with previously published data demonstrating that the rate of new radiographic fracture is high in this patient population ( $46 \%$ ), but kyphoplasty does not increase the risk of subsequent vertebral fractures compared with nonsurgical care by 24 months. ${ }^{(29,30)}$ In the second year, fracture rates were approximately one-fifth those in the first year.

There was no statistically significant difference between groups in the number of patients with subsequent adjacent fractures; approximately half of patients with any subsequent fracture had an adjacent fracture, consistent with other reports. ${ }^{(2)}$ Also consistent with previous data, approximately $40 \%$ of patients in this study had subsequent vertebral fractures that came to clinical attention owing to renewed pain. ${ }^{(31)}$

There were two serious AEs related to kyphoplasty that occurred after 1 year. The first was a recollapse of a treated vertebra with anterior migration of the cement. In retrospect, on review of the X-rays, the migration was visible on X-ray at 3 months but was not reported as a SAE on the case report form until later; follow-up X-rays for patients with VCF are valuable for assessing vertebral/spinal stability. This case involved a thoracolumbar fracture with an intravertebral vacuum cleft and is similar to several other cases treated with kyphoplasty or vertebroplasty reported in the literature. ${ }^{(32)}$ Such cases may or may not require extensive revision surgery; no revision surgery was performed in the patient reported here. The second case was a patient with spondylitis and highlights that intercurrent infection is a risk factor for developing late infection in any implant surgery. Therefore, kyphoplasty patients should be evaluated for the presence of infection and should not be treated until infection has resolved. These SAEs were uncommon and should be monitored.

This is the largest randomized trial of surgical treatment for vertebral fractures, with relatively high rates of follow-up for 2 years and assessment of multiple endpoints compared with standard practice. However, knowledge of treatment assignment may have influenced patient responses or radiologist assess- ments. Nonsurgical care was not standardized across treatment centers but represents common practice.

We conclude that compared with nonsurgical management, balloon kyphoplasty rapidly reduces pain and improves function, disability, and QOL over the course of 2 years without increasing the risk of additional vertebral fractures. Most outcomes are not statistically different at 24 months, but the reduction in pain remains statistically significant at all time points.

\section{Study investigators}

Country of origin (number of patients enrolled for each country), city, and investigator name: Austria (4): Vienna-S. Becker; Belgium (63): Brugge-J Van Meirhaeghe; Liège-V Bex, L Collignon, F Sacré; France (25): Caen - H Huet, C Marcelli; LilleP Chastanet, B Cortet; Paris-M Cohen-Solal, J Laredo; Toulouse-B Mazières, J Railhac; Germany (54): BerlinD Felsenberg; Hannover - L Bastian, C Krettek; HeidelbergC Kasperk, P Meeder; Rosenheim — G Regel; Italy (7): CataniaT Russo; Verona - P Bartolozzi; The Netherlands (6): TilburgPNM Lohle; Sweden (70): Falun — P Fritzell; Malmö-R Hasserius, O Johnell, M Karlsson, A Ohlin; Stockholm-G Ordeberg; Uppsala-M Cornefjord, P Försth; United Kingdom (71): Aberdeen - F Smith, D Wardlaw; London - K Lam, T Sabharwal; Oxford-J Wass, D Wilson.

\section{Disclosures}

SB has received honoraria for consulting from Medtronic Spine, LLC (FREE study), and has received consulting or advisory board fees, lecture fees, and research funding or grant support from Amgen, Eli Lilly, Medtronic Spine, LLC (one additional study), Merck, Novartis, Procter \& Gamble, Sanofi-Aventis, Servier, and Roche-GlaxoSmithKline. JVM has received honoraria for consulting and research funding (FREE and two other studies) from Medtronic Spine, LLC, and has received honoraria for consulting from Stryker and Synthes. LB has received honoraria for consulting and research funding (FREE and two other studies) from Medtronic Spine, LLC. SRC has received honoraria for consulting from Medtronic Spine, LLC (FREE study), and research funding or consultation honoraria from Lilly, Pfizer, Novartis, 
Amgen, Merck, Procter \& Gamble, Zelos, and Organon. JR is employed by the Swedish National Competence Centre for musculoskeletal disorders at Lund University Hospital, Sweden, an organization that has received compensation for work by Medtronic Spine, LLC (FREE and one other study). JBT was employed by and owned stock and stock options in Kyphon, Inc. (now Medtronic Spine, LLC), and is currently employed by Medtronic Spine, LLC, and owns stock options in Medtronic, Inc. $\mathrm{RE}$ has received honoraria or consulting fees from Medtronic Spine, LLC (FREE and one other study), Amgen, AstraZeneca, GlaxoSmithKline, Nastech, Nestle, Fonterra Brands, Novartis, Ono Pharma, Osteologix, Lilly, Pfizer, Sanofi Aventis, Tethys, Unilever, Unipath, Inverness Medical, Procter \& Gamble, Takeda, and the National Osteoporosis Foundation, and the institution has received research funding and/or travel reimbursement from Medtronic Spine, LLC, Lilly, Pfizer, Novartis, Amgen, Procter \& Gamble, GlaxoSmithKline, Fonterra Brands, AstraZeneca, Unilever, Ono Pharma, Servier, Department of Health NIHR, Unipath, Osteologix, Arthritis Research Council, Medical Research Council UK, Crescent Diagnostics, Nittoboseki Company, Ltd., Nestle Foundation, Sanofi Aventis, and the Department of Health, NIHR. KT was employed by and owned stock and stock options in Kyphon, Inc., and is currently employed by Medtronic Spine, LLC. DW has received honoraria for consulting from Medtronic Spine, LLC (FREE study), and Cryolife and has received research funding from Medtronic Spine, LLC (FREE and two other studies), Zimmer, Apatec, and Cryolife.

\section{Acknowledgments}

This study was sponsored and funded by Medtronic Spine, LLC. The authors and study investigators are indebted to the patients who consented to participate in the FREE trial and to all participating staff at the investigational centers. The authors gratefully acknowledge Patricia Segarini, PhD (ApotheCom), for editorial writing assistance and Pete Shabe (Advanced Research Associates) for statistical analysis. SB is senior clinical investigator of the Fund for Scientific Research, Flanders, Belgium (F.W.O. Vlaanderen) and holder of the Leuven University Chair in Gerontology and Geriatrics.

\section{References}

1. Johnell O, Kanis JA. An estimate of the worldwide prevalence and disability associated with osteoporotic fractures. Osteoporos Int. 2006;17:1726-1733.

2. Silverman SL, Minshall ME, Shen W, Harper KD, Xie S. The relationship of health-related quality of life to prevalent and incident vertebral fractures in postmenopausal women with osteoporosis: results from the Multiple Outcomes of Raloxifene Evaluation Study. Arthritis Rheum. 2001;44:2611-2619.

3. Borgstrom F, Zethraeus $\mathrm{N}$, Johnell $\mathrm{O}$, et al. Costs and quality of life associated with osteoporosis-related fractures in Sweden. Osteoporos Int. 2006;17:637-650.

4. Burge R, Dawson-Hughes B, Solomon DH, Wong JB, King A, Tosteson A. Incidence and economic burden of osteoporosis-related fractures in the United States, 2005-2025. J Bone Miner Res. 2007;22:465475.
5. Lyritis GP, Mayasis B, Tsakalakos N, et al. The natural history of the osteoporotic vertebral fracture. Clin Rheumatol. 1989;8:S66-69.

6. Silverman SL. AT The clinical consequences of vertebral compression fracture. Bone. 1992;13 (Suppl 2): S27-S31.

7. Lyles KW, Gold DT, Shipp KM, Pieper CF, Martinez S, Mulhausen PL. Association of osteoporotic vertebral compression fractures with impaired functional status. Am J Med. 1993;94:595-601.

8. Cook DJ, Guyatt GH, Adachi JD, et al. Quality of life issues in women with vertebral fractures due to osteoporosis. Arthritis Rheum. 1993; 36:750-756.

9. Oleksik AM, Ewing S, Shen W, van Schoor NM, Lips P. Impact of incident vertebral fractures on health related quality of life (HRQOL) in postmenopausal women with prevalent vertebral fractures. Osteoporos Int. 2005;16:861-870.

10. Voggenreiter G. Balloon kyphoplasty is effective in deformity correction of osteoporotic vertebral compression fractures. Spine. 2005;30: 2806-2812.

11. Buchbinder $\mathrm{R}$, Osborne $\mathrm{RH}$, Ebeling $\mathrm{PR}$, et al. A randomized trial of vertebroplasty for painful osteoporotic vertebral fractures. N Engl J Med. 2009;361:557-568.

12. Kallmes DF, Comstock BA, Heagerty PJ, et al. A randomized trial of vertebroplasty for osteoporotic spinal fractures. N Engl J Med. 2009;361:569-579.

13. Wardlaw D, Cummings SR, Van Meirhaeghe J, et al. Efficacy and safety of balloon kyphoplasty compared with non-surgical care for vertebral compression fracture (FREE): a randomised controlled trial. Lancet. 2009;373:1016-1024.

14. Garfin SR, Yuan HA, Reiley MA. New technologies in spine: kyphoplasty and vertebroplasty for the treatment of painful osteoporotic compression fractures. Spine. 2001;26:1511-1515.

15. Ware J Jr, Kosinski M, Keller S. SF-36 Physical and Mental Health Summary Scales: A User's Manual. Boston, Massachusetts: The Health Institute, New England Medical Center, 1994.

16. EuroQol G. EQ-5D User Guide. Rotterdam, The Netherlands: EuroQo Group, 1996.

17. Roland M, Fairbank J. The Roland-Morris Disability Questionnaire and the Oswestry Disability Questionnaire. Spine. 2000;25:3115-3124.

18. Farrar JT, Young JP Jr, LaMoreaux L, Werth JL, Poole RM. Clinical importance of changes in chronic pain intensity measured on an 11point numerical pain rating scale. Pain. 2001;94:149-158.

19. Nevitt MC, Thompson DE, Black DM, et al. Effect of alendronate on limited-activity days and bed-disability days caused by back pain in postmenopausal women with existing vertebral fractures. Fracture Intervention Trial Research Group. Arch Intern Med. 2000;160: 77-85.

20. Genant HK, Wu CY, van Kuijk C, Nevitt MC. Vertebral fracture assessment using a semiquantitative technique. J Bone Miner Res. 1993;8:1137-1148.

21. Eastell R, Cedel SL, Wahner HW, Riggs BL, Melton LJ III. Classification of vertebral fractures. J Bone Miner Res. 1991;6:207-215.

22. Jiang G, Eastell R, Barrington NA, Ferrar L. Comparison of methods for the visual identification of prevalent vertebral fracture in osteoporosis. Osteoporos Int. 2004;15:887-896.

23. Mallinckrodt CH, Clark WS, David SR. Accounting for dropout bias using mixed-effects models. J Biopharm Stat. 2001;11:9-21.

24. Dolan P. Modeling valuations for EuroQol health states. Med Care. 1997;35:1095-1108.

25. Walters SJ, Brazier JE. Comparison of the minimally important difference for two health state utility measures: EQ-5D and SF-6D. Qual Life Res. 2005;14:1523-1532.

26. Tosteson AN, Lurie JD, Tosteson TD, et al. Surgical treatment of spinal stenosis with and without degenerative spondylolisthesis: cost-effectiveness after 2 years. Ann Intern Med. 2008;149:845-853. 
27. Strom O, Leonard C, Marsh D, Cooper C. Cost-effectiveness of balloon kyphoplasty in patients with symptomatic vertebral compression fractures in a UK setting. Osteoporos Int. 2010;21:1599-1608.

28. National Institute for $\mathrm{H}$, Clinical $\mathrm{E}$. Guide to the methods of technology appraisal. London, UK: National Institute for Health and Clinical Excellence, 2008.

29. Kasperk C, Grafe IA, Schmitt S, et al. Three-year outcomes after kyphoplasty in patients with osteoporosis with painful vertebral fractures. J Vasc Interv Radiol. 2010;21:701-709.
30. Komp M, Ruetten S, Godolias G. Minimally invasive therapy for functionally unstable osteoporotic vertebral fracture by means of kyphoplasty: prospective comparative study of 19 surgically and 17 conservatively treated patients. J Miner Stoffwechs. 2004;11 (Supplement 1):13-14.

31. Cooper C, Melton LJ. Vertebral fractures. BMJ. 1992;304:793794.

32. Van Meirhaeghe J. Cement displacement after kyphoplasty: a radiographic case study. SpineLine. 11:22-25. 